University of Windsor

Scholarship at UWindsor

$10-11-2018$

\title{
Profound Health Care Discrimination Experienced by Transgender People: Rapid Systematic Review
}

\author{
Luisa Kcomt \\ University of Windsor
}

Follow this and additional works at: https://scholar.uwindsor.ca/socialworkpub

Part of the Social Work Commons

\section{Recommended Citation}

Kcomt, Luisa. (2018). Profound Health Care Discrimination Experienced by Transgender People: Rapid Systematic Review. Social Work in Health Care. https://scholar.uwindsor.ca/socialworkpub/62 has been accepted for inclusion in Social Work Publications by an authorized administrator of Scholarship at UWindsor. For more information, please contact scholarship@uwindsor.ca. 
Social Work

in Health Care

\section{Profound Health Care Discrimination Experienced by Transgender People: Rapid Systematic Review}

\begin{tabular}{|r|l|}
\hline \hline Journal: & Social Work in Health Care \\
\hline \hline Manuscript ID & WSHC-2018-0964.R1 \\
\hline \hline Kanuscript Type: & Original Article \\
\hline \hline Keywords: & $\begin{array}{l}\text { trans*, transgender, Health Care, cisnormativity, cisgenderism, rapid } \\
\text { systematic review }\end{array}$ \\
\hline \hline
\end{tabular}

\section{SCHOLARONE" \\ Manuscripts}


Profound Health Care Discrimination Experienced by Transgender People:

Rapid Systematic Review

Luisa Kcomt

Affiliations: School of Social Work, University of Windsor

Address: 167 Ferry Street, Windsor, Ontario, N9A 0C5, Canada

Email: kcomtl@uwindsor.ca

Telephone: (586) 419-7425

Fax: (586) 228-8836

Acknowledgements: Gratitude is expressed for the assistance of Kevin Gorey, School of Social Work, University of Windsor who provided an internal review of this manuscript.

Funding: This study was supported in part by an Ontario Graduate Scholarship. 


\begin{abstract}
Transgender people experience interpersonal and structural barriers which prevent them from accessing culturally and medically competent health care. This rapid systematic review examined the prevalence of health care discrimination among transgender people in the U.S. and drew comparisons with sexual minority samples and the general U.S. population. Eight primary studies with 35 prevalence estimates were analyzed. The transgender population experience profound rates of discrimination within the U.S. health care system. Compared to sexual minorities, transgender participants appear to be more compromised in their access to health care. Service providers must change structural inequities which contribute to transgender people's invisibility.

Key words: trans*, transgender, health care discrimination, health care access, cisnormativity, cisgenderism, rapid systematic review
\end{abstract}


The term transgender is "widely used to refer to a diverse group of individuals who cross or transcend culturally defined categories of gender" (Bockting, 1999 in Institute of Medicine, 2011, p. 26). It is an "umbrella term for people whose gender identity and/or gender expression differs from the sex they were assigned at birth. Transgender people may or may not decide to alter their bodies hormonally and/or surgically" (National Resource Center on LGBT Aging, 2012, p. 27). Recent data from a population-based survey suggests that $0.6 \%$ of adults in the U.S. (approximately 1.4 million people) identify as transgender (Flores, Herman, Gates, \& Brown, 2016). Transgender health needs are beginning to draw attention from health care providers and researchers, with many practitioners and health care systems finding themselves ill equipped to meet the needs of the transgender population (Lombardi, 2001). Transgender people are a medically underserved population experiencing pervasive discrimination in the health care system (Giblon \& Bauer, 2017; Rodriguez, Agardh, \& Asamoah, 2017). As advocates for social justice, social workers need to understand the barriers which prevent transgender people from accessing medically and culturally competent care.

As a marginalized population, transgender people experience pervasive discrimination in almost every institution and system in their lives. Social research has revealed the many facets of their oppression, all of which have deleterious effects on transgender individuals' health and well-being (Albuquerque et al., 2016; Brandes, 2014; Grant et al., 2011; James et al., 2016; McCann \& Brown, 2017; Winter et al., 2016). The rates of homelessness and poverty, along with disparities in health and education, contribute to the body of evidence regarding housing and employment inequities that they experience and their barriers to access within health care and school systems (Grant et al., 2011; James et al., 2016; Winter et al., 2016). Acts of violence and victimization committed against them are often spurred by transphobia (i.e., irrational fear or 
hatred of transgender people). Many of these crimes remain unreported, as trans individuals are often fearful of further victimization from police officers and discrimination within the criminal justice system (Grant et al., 2011; James et al., 2016; Moolchaaem, Liamputtong, O’Halloran, \& Muhamad, 2015; Winter et al., 2016). Because of their poverty, many trans individuals participate in the underground economy for survival which places them at further risk for health and legal problems (Grant et al., 2011; James et al., 2016; Moolchaaem et al., 2015). This interlocking web of inequities produces and reproduces the social exclusion which sustains their oppression (Grant et al., 2011; James et al., 2016).

While transphobia is often used to explain the direct acts of discrimination and violence committed against trans people on an individual level, this singular focus obscures the systemic social exclusion which occurs at the structural or institutional level, and entrenched within cultural and political contexts (Bauer et al., 2009; Namaste, 2000; Pyne, 2011). The concept of erasure has been used to explain the interlocking systems of oppression which render transgender people invisible and ultimately undermines the possibility of a trans identity (Namaste, 2000). Bauer et al. (2009) advanced this concept further by explaining how erasure manifests within the health care environment through informational systems and institutional policies and practices.

Knowledge production impacts information dissemination. Informational erasure refers to the lack of knowledge produced about trans people and maintaining the assumption that such knowledge is non-existent even when there is evidence to counter this assumption (Bauer et al., 2009). For example, health researchers often hold an erroneous assumption that all research participants are cisgender (people whose gender identity aligns with their assigned sex at birth) and thus the questions which are important to the trans population are never brought into focus. This contributes to the lack of information about trans-specific health issues in educational 
curricula and textbooks. When information about trans people is included, it is often integrated into lesbian, gay, bisexual, and transgender (LGBT) issues, thereby conflating gender identity with sexual orientation and obscuring the specific needs of the transgender population. The paucity of research resulting in a dearth of information renders health care providers poorly equipped to handle the health needs of their trans patients. Many trans individuals find themselves having to educate their health care providers about their needs. Therefore, informational erasure maintains their invisibility and social exclusion (Bauer et al., 2009; Cruz, 2014; Reisner et al., 2014).

Institutional erasure manifests as policies or organizational infrastructure which exclude the existence of trans identities or trans bodies. Examples include intake forms which utilize a binary categorization for sex/gender, settings which use sex segregation as part of their provision of service (e.g., hospital wards, shelters, etc.), and billing systems which require concordance between listed sex and anatomy to allow for billing of sex specific procedures:

... trans people are often forced to choose between accessing services according to their birth sex or foregoing services entirely... Broadly, trans people seeking health care are often faced with the acute realization that many providers are not familiar with or willing to accept the possibility of trans identities, which impacts both the availability and quality of care. Embedded in this particular configuration of institutional erasure is a politics of recognition regarding being in the appropriate place or possessing the correct anatomy to be provided service. (Bauer et al., 2009, p. 355)

Trans patients who have disclosed their gender identity have experienced active, direct discrimination from health care providers such as the denial of care, abuse, or harassment (Fredriksen-Goldsen et al., 2011; Grant et al., 2011; James et al., 2016; Lambda Legal, 2010; 
Reisner et al., 2014). To avoid discrimination, many trans patients opt not to disclose their trans identity by passing as cisgender, or engage in selective disclosure based on their perception of the health care provider's attitude, the setting, or the medical need. This complex disclosure process shapes the access to care and impact health outcomes (Bauer et al., 2009; Cruz, 2014). "Disclosure involves the risk of denial of care or mistreatment; lack of disclosure involves the risk of inappropriate health care and possible unintentional disclosure through medical examinations or testing" (Bauer et al., 2009, p. 357). The informational and institutional erasure can be both active and passive, and result in barriers to access which reinforce the marginalization of trans patients in their engagement with health care systems.

Sadly, because of their lack of training on the needs of the trans population and trans health issues, many health care providers reflect society's cisgenderist attitudes and cisnormative assumptions. Even if they do not align with cisgenderist ideology on an individual basis, health care providers often work in broader social contexts which produce and perpetuate cisnormativity and cisgenderism at systemic and structural levels. Underpinned by transphobia and reinforced by erasure, cisnormativity fosters the assumption that all people are cisgender. These assumptions are so pervasive that health care providers and institutions do not question the experience of gender, do not anticipate the possibility of a trans existence, and thus are unprepared when such a person seeks their services. Paradoxically, the invisibility of trans identities creates a sudden hyper-visibility when a trans patient enters the health care system such that these situations are regarded as anomalies which challenge the process of medically and culturally competent service delivery (Bauer et al., 2009; Pyne, 2011).

Cisnormativity breeds cisgenderism which refers to the privileging of non-trans identities. Cisgenderism can occur through both unintentional and well-intentioned practices. 
Examples of cisgenderism may include (a) pathologizing (i.e., characterizing a person's gender identity as disordered); (b) misgendering (i.e., classifying individuals in a way that is inconsistent with their gender identity); (c) marginalizing (i.e., regarding a person's gender identity as weird or strange); (d) coercive queering (i.e., imposing a queer or LGBT label on trans people who identify as heterosexual and assuming that they have the same needs as those in same-gender relationships); and (e) objectifying biological language (i.e., using language which describes a person's assumed physical characteristics such as female-to-male or FTM) (Ansara, 2015). The conceptual lens of informational and institutional erasure, cisnormativity, and cisgenderism bring the systemic marginalization of trans identities into focus and confront the embodied privilege of the cisgender identity. It captures the nuances of discrimination and the system that empowers it, impacting transgender people's ability to access appropriate health care.

Health care access is often characterized as the ability and ease of the consumer to seek and obtain needed services from providers or institutions, the cost of health care, and the characteristics of health care providers which may impact service delivery. In their systematic review of access to health care, Levesque, Harris, and Russell (2013) conceptualized accessibility as consisting of the following dimensions: (a) approachability (e.g., information regarding available treatments and services, outreach activities, transparency, etc.); (b) acceptability (e.g., professional values and norms, sociocultural factors which impact the consumer's level of acceptance to aspects of the service, perceived appropriateness of the consumer seeking care, etc.); (c) availability and accommodation (e.g., geographic location of the service, hours of operation, building accessibility, presence and qualification of the health professional, modes of provision of services, etc.); (d) affordability (e.g., capacity of consumers to spend resources and time to utilize services, direct costs of services, indirect costs such as 
travel time, opportunity costs related to loss of income, etc.); and (e) appropriateness (e.g., the fit between the services and the consumers' needs, the technical and interpersonal quality of the services provided). Because of cisnormativity and cisgenderism, each of these dimensions of accessibility is compromised for trans communities. This can occur directly in the form of overt discrimination (such as a trans patient's experience of being denied care or receiving physical or verbal abuse from a health care provider which are impediments to availability, acceptability, and appropriateness) or indirectly as a secondary outcome of discrimination in other systems (such as employment inequity resulting in lack of employer sponsored health insurance, thereby impacting affordability).

To explore evidence of transgender related discrimination in health care and the pervasive ways in which cisnormativity and cisgenderism impact health care accessibility, the following research questions were formulated de novo for this rapid review:

1. What is the prevalence of health care discrimination among transgender people in the

$$
\text { U.S.? }
$$

2. Is the prevalence of health care discrimination greater among transgender people compared to sexual minority group members or members of the general U.S. population?

\section{Methods}

\section{Study Procedures}

Rapid review methods utilizing streamlined techniques were employed by a single investigator. This lessened the time required to complete this study from greater than 12 months to less than 6 months (Ganann, Ciliska, \& Thomas, 2010; Tricco et al., 2015). Both peer reviewed and gray literature (i.e., non-peer reviewed research reports) were reviewed. Because of the scarcity of research on transgender populations coupled with their frequent subsummation 
within LGBT research, the following search terms were used: (LGBT or lesbian or gay or bisexual or transgender) and (health care discrimination). This allowed for comparisons of prevalence rates between transgender participants and their LGB counterparts. Using the date frame of January 1, 2010 to June 15, 2018, the following electronic databases were searched: LGBT Life, Social Work Abstracts, Social Services Abstracts, Sociological Abstracts, PsycINFO, PubMed, ProQuest Dissertations and Theses Global, Web of Science ${ }^{\mathrm{TM}}$ Conference Proceeding Citation Indexes—Science and Social Science \& Humanities, and Google Scholar. In addition, searches were augmented with snowball searches of reference lists of retrieved articles or research reports. The search was limited to publications in English. Retrieved were 2470 conceptually relevant, duplicated manuscripts.

Subsequently, the studies had to meet the following inclusion criteria:

1. The studies provided prevalence estimates of barriers to health care access or health care discrimination experienced by LGBT or transgender participants

2. The studies were conducted in the U.S.

3. The prevalence rates were obtained from national or state-specific samples Only primary independent studies were selected; secondary analyses which examined the separate mediator or moderator relationships within the primary studies were excluded. Studies which examined the prevalence of health care discrimination in other countries were excluded because the health care system in the U.S. takes place within its own cultural, economic, and political milieu. Health care access in the U.S. is dependent, in large part, on employer sponsored health insurance. Therefore, its infrastructure consists of processes and systemic barriers which may be different from that of other high-income countries. There were eight primary studies which met the inclusion criteria for this rapid review. They are noted in the reference section 
with an asterisk.

\section{Analysis of Prevalence Estimates}

Survey-based prevalence estimates of barriers to health care access among transgender people were reviewed. A prevalence estimate is the proportion of a population exhibiting a certain condition or behavior within a given time-frame. Using Levesque et al.'s (2013) conceptual framework of health care accessibility, nine variables were extrapolated from the eight studies which resulted in 35 prevalence estimates. The access barrier variables were: (a) being denied care; (b) medical providers' lack of knowledge or had to educate Primary Care Physician (PCP); (c) lack health insurance; (d) health care professionals using harsh or abusive language; (e) health care professionals being physically rough or abusive; (f) out to health care provider about being transgender; (g) verbal harassment in a health care setting; (h) physically attacked in a health care setting; (i) do not have a regular PCP. These variables exhibit the ways in which cisnormativity and cisgenderism manifest itself within the U.S. health care system.

The prevalence estimates for each study sample were extracted from the eight primary studies and reported as percentages along with their normal 95\% confidence intervals (CI) (Fleiss, Levin, \& Paik, 2003). If a study examined the aggregated LGBT population and the transgender subpopulation, these were estimated separately. Some of the studies provided prevalence estimates of general populations. This offered an opportunity to draw comparisons and highlight disparities between transgender and general (state) populations.

Medians were used in describing the prevalence outcomes of trans people's experience of health care access barriers. The chi-square statistic $\left(\chi^{2}\right)$ was used to calculate the statistical significance of the comparison between the transgender population and their LGB counterparts; most of these comparisons occurred between samples within the same study. Prevalence ratios 
(PR) and the $95 \%$ CI derived from $\chi^{2}$ tests were used to report the practical significance of the between group comparisons of the transgender population and their LGB counterparts within the same study sample or the U.S. general population as referenced within the primary study (Fleiss et al., 2003). A PR is the ratio of one group's prevalence estimate to another group's prevalence estimate. PR values greater than 1.00 reflect a trans disadvantage. The difference between two groups was considered statistically significant $(\mathrm{p}<0.05)$ when the $95 \%$ CI did not include the null value of 1.00. Because the studies varied in their measurement of prevalence over a temporal period (i.e., lifetime prevalence versus prevalence within the past 12 months), medians and PR values were calculated only when the researchers used the same temporal period in measuring prevalence.

\section{Results}

\section{Sample Description}

Surveys from an aggregated sample of 43,570 lesbian, gay, bisexual, transgender, questioning (individuals who are still in the process of exploring and discovering their sexual orientation, gender identity, and gender expression), and intersex (individuals whose sexual anatomy or chromosomes do not fit the traditional markers of male and female) respondents were collected over the 8 studies. Four of the surveys were in specific states: Virginia (Bradford, Reisner, Honnold, \& Xavier, 2013), Colorado (One Colorado, 2014), Massachusetts (Reisner et al., 2014), and Hawaii (Stotzer, Ka'opua, \& Diaz, 2014). The remaining samples were drawn nationally. Five of the studies were exclusively transgender. The remaining studies surveyed the LGBT population — one of which included questioning and intersex respondents in their sample. Given the difficulty in accessing the sexual and gender minority populations, all the studies used a non-probability sampling method (i.e., convenience, snowball, or respondent driven sampling). 
All the studies used online methods and all except one study augmented these with hard copy questionnaires or personal interviews. Two of the studies were published in peer reviewed journals (Bradford et al., 2013; Stotzer et al., 2014) while the rest were non-peer reviewed research reports (Fredriksen-Goldsen et al., 2011; Grant et al., 2011; James et al., 2016; Lambda Legal, 2010; One Colorado, 2014; Reisner et al., 2014).

\section{Barriers to Health Care Accessibility}

Many transgender people reported having negative experiences when interfacing with the health care system. As can be seen in Table 1, over a quarter of the transgender people studied had been denied care by a health care professional at least once in their lifetimes (19-40\%, median $=27 \%$ ). When the samples who experienced a lifetime prevalence of being denied care were aggregated (Lambda Legal, 2010; Fredriksen-Goldsen et al., 2011; Grant et al., 2011), results reveal that transgender individuals were more than twice as likely as their LGB counterparts to be denied care, $\chi^{2}(1, \mathrm{~N}=14,432)=390.44, \mathrm{p}<0.05, \mathrm{PR}=2.34(95 \%$ CI 2.15 , 2.55). Between group comparisons within the same study show an even greater disadvantage: Lambda Legal (2010) and Fredriksen-Goldsen et al. (2011) show that transgender individuals were over three times more likely to be denied care than their LGB counterparts. Over a third of the transgender participants had encounters with health care professionals who were not informed about trans related health issues and had to teach these providers about their health needs to receive appropriate care $(20-50 \%$ lifetime prevalence, median $=35 \%)$. Approximately 1 in 7 transgender individuals do not have health insurance $(14-19 \%$, median $=14 \%)$. When compared to the general population, transgender people were $27 \%$ more likely to lack health insurance $(\mathrm{PR}=1.27)$. Counter to their professional values and ethics, health care providers often treat transgender people harshly, either in the form of verbal or physical abuse. Within the 
past 12 months of the survey, one in twenty transgender individuals had experienced health care providers using harsh or abuse language towards them and one in fifty such individuals had received physically rough or abusive treatment. Compared with their LGB counterparts, transgender people were almost twice as likely to have been verbally abused: $20.9 \%$ versus $10.7 \%, \chi^{2}(1, \mathrm{~N}=5,422)=59.59, \mathrm{p}<0.05, \mathrm{PR}=1.95(95 \% \mathrm{CI} 1.65,2.30)$. Transgender people were also twice as likely to have been physically abused by their health provider: $7.8 \%$ versus $4.1 \%, \chi^{2}(1, \mathrm{~N}=5,422)=19.55, \mathrm{p}<0.05, \mathrm{PR}=1.90(95 \% \mathrm{CI} 1.43,2.52)$. Over two-thirds of the transgender population have disclosed their gender identity to their health provider (43-79\%, median $=70 \%$ ). This means that almost one in three transgender individuals have chosen not to disclose their gender identity which may result in a compromised ability to receive appropriate treatment. Finally, the study by Stotzer et al. (2014) showed that sexual and gender minorities, in general, were more likely to lack a regular physician compared to the general state population. More specifically, $40 \%$ of transgender people were estimated to not have a regular PCP (Bradford et al., 2013). Considering their negative experiences with health care providers, it is not surprising, then, that almost one-quarter of transgender people have delayed receiving necessary medical care $(19-40 \%$, median $=23 \%)$ and preventive medical care $(24 \%)$ in the past 12 months (Table 2).

\section{Discussion}

LGBT advocates have made some advancements in creating visibility and demanding equity. There is, however, still a long road to establishing inclusivity_especially within heteronormative and cisnormative health care systems. Although the experience of discrimination may be common among LGBT individuals because of their minority status, the results of this rapid review provide evidence of transgender people's consistent disadvantages in 
accessing health care. They are the most marginalized subgroup within the LGBT community, experiencing health care discrimination at higher rates than their LGB cohorts. These results substantiate the heterogeneity of the LGBT population and reaffirm the need to increase health care providers' understanding of the unique needs of the transgender population.

Other systematic reviews of the empirical research have revealed the discrimination and social exclusion experienced by transgender individuals generally (McCann \& Brown, 2017; Moolchaaem et al., 2015), their interface with the health care system more specifically (Lerner \& Robles, 2017), and their increased vulnerability at the end of life in particular (Kcomt \& Gorey, 2017). Moreover, researchers have discovered that among the LGBT population, transgender participants were more likely to report the negative effects of disclosure to their provider and thus were more likely to delay seeking health care than their cisgender LGB counterparts (Macapagal, Bhatia, \& Greene, 2016). Additionally, their recognizability as a transgender person was significantly associated with their perceived discrimination in health care (Rodriguez et al., 2017). A significant relationship exists between delaying care because of fear of discrimination and worse general and mental health among transgender adults (Seelman, Colon-Diaz, LeCroix, Xavier-Brier, \& Kattari, 2017). The avoidance of or delayed entry into health care can result in health disparities which contribute to morbidity and mortality.

Affordability and availability are important dimensions of health care access. Within the interlocking web of oppression, transgender people may experience employment based discrimination and financial inequities which impact their ability to have health insurance or pay for the direct and indirect costs of health care. Moreover, finding a trans-affirming health care provider within reasonable proximity can be challenging (Grant et al., 2011; James et al., 2016). The lack of health insurance and the unavailability of trans-affirming health care can have a 
direct impact on health outcomes. For example, unable to obtain hormone therapy through a health care provider, a trans person may resort to using street hormones which can have dire consequences (White-Hughto, Reisner, \& Pachankis, 2015).

The need for more population specific studies on transgender health has been recognized (Institute of Medicine, 2011). Within the transgender community itself, there exists multiple diversities which impact the transgender person's experience of discrimination. Access to health care is influenced by gender identity; differences exist between transgender subgroups in their experience of health care access barriers and health care utilization (Gonzales \& Henning-Smith, 2017). For example, studies have revealed that trans men have a greater tendency than trans women to delay health care due to the fear of discrimination (Cruz, 2014; Jaffee, Shires, \& Stroumsa, 2016). Furthermore, researchers have identified the increased disadvantages of transgender individuals who belong to more than one marginalized community (e.g., ethnic/racial minority, low income and visually non-conforming), as these individuals experience even more prevalent discrimination and substandard care (Bradford et al., 2013; Grant et al., 2011; Jaffee et al., 2016; Kattari, Walls, Whitfield, \& Langenderfer-Magruder, 2015, 2017; Lambda Legal, 2010; Shires \& Jaffee 2015). Other research has revealed that transgender men have less access to health care than cisgender adults. Yet, these differences were not statistically significant when sociodemographic factors were controlled, which suggest an intersectional approach to practice in order to mitigate inequities (Seelman, Miller, Fawcett, \& Cline, 2018). Further research is needed to explore the intersectionality of gender identity with other diversities (e.g., race/ethnicity, socioeconomic status and age) to understand how the multiplicity of marginalized identities may impact health care access.

This rapid review focused on transgender people's access to health care within the U.S. 
However, Canadian research provides convergent evidence that transgender people experience discrimination even within the single payer system in Canada. While transgender patients in Canada may not have to struggle with issues of affordability because of universal health insurance, they do encounter discriminatory treatment from health care providers like their American counterparts. Over half (52\%) of trans Ontarians have had negative experiences related to their trans identity when seeking emergency department (ED) services including being denied care (10\%), receiving hurtful or insulting language (32\%), or having to educate the ED provider about trans health issues "some" or "a lot" (54\%) (Bauer, Scheim, Deutsch, \& Massarella, 2014). Moreover, approximately half of trans Ontarians who had a family physician felt uncomfortable discussing trans health issues with their doctor (Bauer, Zong, Scheim, Hammond, \& Thind, 2015). Equal availability of health care does not necessarily result in equal access. Transgender individuals in Canada remain a medically underserved population (Giblon \& Bauer, 2017). The marginalization of trans people and the lack of cultural competence among health care providers is pervasive across health systems. Future research should include a systematic review of international studies which explore the prevalence of health care discrimination experienced by transgender people in other countries.

A consequence of informational erasure is the lack of training for health care providers on trans health issues. Health care providers have begun to recognize their own knowledge deficits and skills in treating transgender patients. They have also identified the structural barriers within their health care systems which hinder the provision of medically and culturally competent care (Lurie, 2005; Snelgrove, Jasudavisius, Rowe, Head, \& Bauer, 2012). Additional research is needed to gain a contextual understanding of providers' perspectives regarding their training needs and the systemic barriers they experience. This information can be used to address 
knowledge deficits and create policy changes at the mezzo and macro level.

\section{Limitations}

While these studies were instrumental in elucidating the prevalence of discrimination and health related behaviors experienced by sexual and gender minority communities, there were some limitations to this research which should be highlighted. First, all the studies were descriptive in nature and utilized a cross sectional survey design; they measured exposure or conditions at the same point in time which did not allow for causal inference. Second, because sexual and gender minorities are marginalized populations which are difficult to access, all the studies used a convenience or snowball sampling method. These non-probability samples are not likely to have been representative of the diversities within the LGBT population. For example, most of the research participants were non-Hispanic white people. Third, all the studies used online surveys as a data collection method, which meant that most of the participants had internet access. Online surveys can be effective in accessing populations which are difficult to reach because of their fear of stigma and discrimination. However, one drawback is that the researchers were less likely to have accessed the most marginalized segments of the population and thus were under-reporting the social determinants of health and illness (Wright, 2005). In addition, although state specific samples were helpful to highlight the salient disadvantages experienced by sexual and gender minority populations compared to the general population, the nonprobability sampling method meant that the results of the study may not be generalizable to sexual and gender minority populations in other states. The acceptance of diversity is geopolitical in the U.S., with certain states being more progressive than others in passing legislation to protect the rights of LGBT members. Lastly, the inclusion criteria for the transgender subgroup varied between studies. Some studies limited their focus to individuals 
who lived as the gender opposite to the one they were assigned to at birth while others included participants who were gender non-conforming (individuals whose behavior and appearance do not conform to societal expectations for a given gender). Although this difference highlights the diversity which exists with the transgender subgroup, it also limits the generalizability of the findings to other transgender or gender non-conforming populations.

\section{Implications for Social Work Practice}

Health care providers' attitudes about sexual orientation, gender identity, and gender expression affect the way that they relate to LGBT patients. Whether intended or not, health care providers can display homophobic, heterosexist, transphobic, and cisgenderist attitudes and behaviors which mirror societal values. These biases limit their ability to create a therapeutic alliance with LGBT patients and create a structural barrier to accessing quality care. Researchers and practitioners have underscored the need to develop cultural competency and capacity building in serving LGBT clients in general (Adams, 2016; Hillman, 2016; Moone, Croghan, \& Olson, 2016; National Resource Center on LBGT Aging, 2012; Van Den Bergh \& Crisp, 2004; Wheeler \& Dodd, 2011; Wilkerson, Rybicki, Barber, \& Smolenski, 2011; Zuzelo, 2014) and transgender individuals in particular (Ansara, 2015; Hyderi, Angel, Madison, Perry, \& Hagshenas, 2016; Marshall, Pickle, \& Lawlis, 2017; Porter et al., 2016). To affirm and support the LGBT community, social workers must first examine their own conscious and unconscious biases and address their knowledge deficits related to the needs of sexual and gender minority populations. As advocates advancing health equity for vulnerable and disadvantaged populations, social workers must confront the barriers to health care access and engage in policy initiatives which have the potential to eradicate the health disparities experienced by LGBT people (Wheeler \& Dodd, 2011). Social workers have an ethical responsibility to challenge social 
injustice and to engage in social change efforts by promoting awareness of oppression and diversity (NASW, 2017).

The NASW's Standards and Indicators for Cultural Competence in Social Work Practice (2015) also informs the discussion about practice implications with sexual and gender minority populations. Cultural competence is defined as knowledge, skills, and attitudes enabling effective service delivery to diverse populations. Social workers must develop an awareness of their own position of power and privilege vis-à-vis the client populations that they serve. Using an intersectionality approach to practice, culturally competent social workers acknowledge the multiplicity of identities and how this impacts the experience of privilege and oppression. They examine "forms of oppression, discrimination, and domination through diversity components of race and ethnicity, immigration and refugee status, religion and spirituality, sexual orientation and gender identity and expression, social class, and abilities" (NASW, 2015, p. 10). They are aware of the heterogeneity within the sexual and gender minority population and are sensitive to the challenges faced by those who identify with more than one marginalized community. Culturally competent social workers can educate other health professionals and use their influence as an integral part of health care teams. Heterosexism, heteronormativity, cisgenderism and cisnormativity occur at multiple levels and thus, a multi-pronged approach must be used in the interventions to eliminate them. The NASW standards should be applied at the micro, mezzo, and macro levels of practice and encourages social workers to recognize and challenge individual, interpersonal, and institutional oppression (NASW, 2015).

\section{Conclusion}

In recent years, a national discourse has been taking place in the U.S. about transgender rights - from their ability to use public restrooms to their inclusion in the military. As concepts 
like erasure, cisnormativity, and cisgenderism emerge in the social consciousness, health care providers are challenged to reexamine the dominant experience of gender and to dislocate it from its place of privilege. Researchers, advocates, and allies alike are making an impassioned plea for organizations to shift their transphobic gaze by looking beyond the conventional binary categories of gender to create an inclusive environment for transgender and gender nonconforming communities. A candid self-assessment of institutional policies and practices is required to change structural inequities which contribute to transgender people's invisibility. Because accessibility is a social determinant of health, a call to action is imperative. Not only do poor health outcomes impact quality of life for trans people and their families, but they also result in long term socioeconomic consequences through increased direct, indirect, and opportunity costs. When marginalized groups are subjugated through systemic oppression, their opportunities to make a social contribution are suppressed. Thus, transgender rights are not simply about achieving equitable access for a specific group but rather, it is also about creating an unrealized gain for the rest of society. 


\section{References}

Adams, M. (2016). An intersectional approach to services and care for LGBT elders. Journal of the American Society on Aging, 40(2), 94-100.

Albuquerque, G. A., de Lima Garcia, C., da Silva Quirino, G., Alves, M. J. H., Belém, J. M., dos Santos Figueiredo, F. W.,...Adami, F. (2016). Access to health services by lesbian, gay, bisexual, and transgender persons: Systematic literature review. BMC International Health and Human Rights, 16(2). doi: 10.1186/s12914-015-0072-9

Ansara, Y. G. (2015). Challenging cisgenderism in the ageing and aged care sector: Meeting the needs of older people of trans and/or non-binary experience. Australasian Journal of Ageing, 34(2), 14-18. doi: 10.1111/ajag.12278

Bauer, G. R., Hammond, R., Travers, R., Kaay, M., Hohenadel, K., M., \& Boyce, M. (2009). “I don't think this is theoretical; this is our lives": How erasure impacts health care for transgender people. Journal of the Association of Nurses in AIDS Care, 20(5), 348-361. doi:10.1016/j.jana.2009.07.004

Bauer, G. R., Scheim, A. I., Deutsch, M. B., \& Massarella, C. (2014). Reported emergency department avoidance, use, and experiences of transgender persons in Ontario, Canada: Results from a respondent-driven sampling survey. Annals of Emergency Medicine, 63(6), 713-720. doi: 10.1016/j.annemergmed.2013.09.027

Bauer, G. R., Zong, X., Scheim, A. I., Hammond, R., \& Thind, A. (2015). Factors impacting transgender patients' discomfort with their family physicians: A respondent-driven sampling survey. PLoS ONE, 1O(12), e0145046. doi:10.1371/journal.pone.0145046

*Bradford, J., Reisner, S. L., Honnold, J. A., \& Xavier, J. (2013). Experiences of transgenderrelated discrimination and implications for health: Results from the Virginia Transgender 
Health Initiative Study. American Journal of Public Health, 103(10), 1820-1829. doi:

10.2105/AJPH.2012.300796

Brandes, A. (2014). The negative effect of stigma, discrimination, and the health care system on the health of gender and sexual minorities. Law \& Sexuality, 23, 155-178.

Cruz, T. M. (2014). Assessing access to care for transgender and gender nonconforming people: A consideration of diversity in combating discrimination. Social Science \& Medicine 110, 65-73. doi: 10.1016/j.socscimed.2014.03.032

Fleiss, J.L., Levin, B., \& Paik, M.C. (2003). Statistical methods for rates and proportions (3rd ed.). New York, NY: John Wiley \& Sons. doi: 10.1002/0471445428

Flores, A. R., Herman, J. L., Gates, G. J., \& Brown, T. N. T. (2016). How many adults identify as transgender in the United States? Retrieved from https://williamsinstitute.law.ucla.edu/wp-content/uploads/How-Many-Adults-Identify-asTransgender-in-the-United-States.pdf

*Fredriksen-Goldsen, K. I., Kim, H.-J., Emlet, C. A., Muraco, A., Erosheva, E. A., Hoy-Ellis, C. P., Goldsen, J., \& Petry, H. (2011). The aging and health report: Disparities and resilience among lesbian, gay, bisexual, and transgender older adults. Seattle: Institute for Multigenerational Health. Retrieved from http://caringandaging.org/wordpress/wpcontent/uploads/2011/05/Full-Report-FINAL-11-16-11.pdf

Ganann, R., Ciliska, D., \& Thomas, H. (2010). Expediting systematic reviews: Methods and implications of rapid reviews. Implementation Science, 5, 56. doi: $10.1186 / 1748-5908-5-56$

Giblon, R. \& Bauer, G. R. (2017). Health care availability, quality, and unmet need: a comparison of transgender and cisgender residents of Ontario, Canada. BMC Health 
Services Research, 17, 283. doi: 10.1186/s12913-017-2226-z

*Grant, J. M., Mottet, L., Tanis, J. E., Harrison, J., Herman, J., \& Keisling, M. (2011). Injustice at every turn: A report of the national transgender discrimination survey. Washington, DC: National Center for Transgender Equality. Retrieved from http://www.thetaskforce.org/static_html/downloads/reports/reports/ntds_full.pdf

Gonzales, G. \& Henning-Smith, C. (2017). Barriers to care among transgender and gender noncomforming adults. The Milbank Quarterly, 95(4), 726-748. doi: 10.1111/14680009.12297

Hillman, J. (2016). Understanding care disparities among older lesbian, gay, bisexual, and transgender (LGBT) adults: Recommendations for culturally competent care. Journal of Gerontology and Geriatric Research, 5(5), 1-2. doi: 10.4172/2167-7182.1000345

Hyderi, A., Angel, J., Madison, M., Perry, L. A., \& Hagshenas, L. (2016). Transgender patients: Providing sensitive care. The Journal of Family Practice, 65(7), 450-461.

Institute of Medicine. (2011). The health of lesbian, gay, bisexual, and transgender people: Building a foundation for better understanding. Washington, DC: Institute of Medicine. Retrieved from https://iom.nationalacademies.org/Reports/2011/The-Health-of-LesbianGay-Bisexual-and-Transgender-People.aspx

Jaffee, K. D., Shires, D. A., \& Stroumsa, D. (2016). Discrimination and delayed health care among transgender women and men: Implications for improving medical education and health care delivery. Medical Care, 54(11), 1010-1016. doi:

10.1097/MLR.0000000000000583

*James, S. E., Herman, J. L., Rankin, S., Keisling, M., Mottet, L., \& Anafi, M. (2016). The report of the 2015 U.S. Transgender Survey. Washington, DC: National Center for 
Transgender Equality. Retrieved from

http://www.transequality.org/sites/default/files/docs/usts/USTS\%20Full\%20Report\%20\%20FINAL\%201.6.17.pdf

Kattari, S. K., Walls, N. E., Whitfield, D. L., \& Langenderfer-Magruder, L. (2015). Racial and ethnic differences in experiences of discrimination in accessing health services among transgender people in the United States. International Journal of Transgenderism, 16, 6879. doi: 10.1080/15532739.2015.1064336

Kattari, S. K., Walls, N. E., Whitfield, D. L., \& Langenderfer-Magruder, L. (2017). Racial and ethnic differences in experiences of discrimination in accessing social services among transgender/gender nonconforming people. Journal of Ethnic \& Cultural Diversity in Social Work, 26(3), 217-235. doi: 10.1080/15313204.2016.1242102

Kcomt, L. \& Gorey, K. (2017). End-of-life preparations among lesbian, gay, bisexual and transgender people: Integrative review of prevalent behaviors. Journal of Social Work in End-of-Life and Palliative Care, 13(4), 284-301. doi: 10.1080/15524256.2017.1387214

*Lambda Legal. (2010). When health care isn't caring: Lambda Legal's survey of discrimination against LGBT people and people with HIV. New York, NY: Lambda Legal. Retrieved from https://www.lambdalegal.org/sites/default/files/publications/downloads/whcicreport_when-health-care-isnt-caring.pdf

Lerner, J. E. \& Robles, G. (2017). Perceived barriers and facilitators to health care utilization in the United States for transgender people: A review of recent literature. Journal of Health Care for the Poor and Underserved 28, 127-152. doi: 10.1353/hpu.2017.0014

Levesque, J., Harris, M. F., \& Russell, G. (2013). Patient-centered access to health care: 
conceptualizing access at the interface of health systems and populations. Journal for Equity in Health, 12(18), 1-9. doi: 10.1186/1475-9276-12-18

Lombardi, E. (2001). Enhancing transgender health care. American Journal of Public Health, 91(6), 869-872.

Lurie, S. (2008). Identifying training needs of health-care providers related to treatment and care of transgendered patients: A qualitative needs assessment conducted in New England. International Journal of Transgenderism, 8(2-3), 93-112. doi: 10.1300/J485v08n02_09

Macapagal, K., Bhatia, R., \& Greene, G. J. (2016). Differences in healthcare access, use, and experiences within a community sample of racially diverse lesbian, gay, bisexual, transgender, and questioning emerging adults. LGBT Health, 3(6), 434-442. doi: 10.1089/lgbt.2015.0124

Marshall, A., Pickle, S., \& Lawlis, S. (2017). Transgender medicine curriculum: Integration into an organ system-based preclinical program. MedEdPORTAL Publications.13,10536. doi: 10.15766/mep_2374-8265.10536

McCann, E. \& Brown, M. (2017). Discrimination and resilience and the needs of people who identify as Transgender: A narrative review of quantitative research studies. Journal of Clinical Nursing, 26, 4080-4093. doi: 10.1111/jocn.13913

Moolchaem, P., Liamputtong, P., O'Halloran, P., \& Muhamad, R. (2015). The lived experiences of transgender persons: A meta-synthesis. Journal of Gay \& Lesbian Social Services, 27, 143-171. doi: 10.1080/10538720.2015.1021983

Moone, R. P., Croghan, C. F., \& Olson, A. M. (2016). Why and how providers must build culturally competent, welcoming practices to serve LGBT elders. American Society on Aging, 40(2), 73-77. 
Namaste, V. K. (2000). Invisible lives: The erasure of transsexual and transgendered people. Chicago, IL: The University of Chicago Press.

NASW (National Association of Social Workers). (2015). Standards and indicators for cultural competence in social work practice. Washington, DC: National Association of Social Workers. Retrieved from https://www.socialworkers.org/LinkClick.aspx?fileticket=7dVckZAYUmk\%3D\&portalid $\underline{=0}$

NASW (National Association of Social Workers). (2017). Code of Ethics of the National Association of Social Workers. Washington, DC: National Association of Social Workers. Retrieved from https://www.socialworkers.org/About/Ethics/Code-ofEthics/Code-of-Ethics-English

National Resource Center on LBGT Aging. (2012). Inclusive services for LGBT older adults: A practical guide to creating welcoming agencies. Retrieved from http://www.lgbtagingcenter.org/resources/resource.cfm?r=487

*One Colorado. (2014). Transparent: The state of transgender health in Colorado. Denver, CO: One Colorado Education Fund.

Porter, K. E., Brennan-Ing, M., Chang, S. C., dickey, 1. m., Singh, A. A., Bower, K. L., \& Witten, T. M. (2016). Providing competent and affirming services for transgender and gender nonconforming older adults. Clinical Gerontologist, 39(5), 366-388. doi: $10.1080 / 07317115.2016 .1203383$

Pyne, J. (2011). Unsuitable bodies: Trans people and cisnormativity in shelter services. Canadian Social Work Review, 28(1), 129-137.

*Reisner, S. L., White, J. M., Dunham, E. E., Heflin, K., Begenyi, J., Cahill, S., \& The Project 
Voice Team. (2014). Discrimination and health in Massachusetts: A statewide survey of transgender and gender nonconforming adults. Boston, MA: The Fenway Institute, Fenway Health.

Rodriguez, A., Agardh, A., \& Asamoah, B. O. (2017). Self-reported discrimination in health-care settings based on recognizability as transgender: A cross-sectional study among U.S. citizens. Archives of Sexual Behavior. doi: 10.1007/s10508-017-1028-z

Seelman, K. L., Colón-Diaz, M. J. P., LeCroix, R. H., Xavier-Brier, M., \& Kattari, L. (2017). Transgender Noninclusive Healthcare and Delaying Care Because of Fear: Connections to General Health and Mental Health Among Transgender Adults. Transgender Health, 2(1), 17-28. http://doi.org/10.1089/trgh.2016.0024

Seelman, K. L., Miller, J. F., Fawcett, Z. E. R., \& Cline, L. (2018). Do transgender men have equal access to health care and engagement in preventive health behaviors compared to cisgender adults? Social Work in Health Care. doi: 10.1080/00981389.2018.1462292

Shires, D. A. \& Jaffee, K. (2015). Factors associated with health care discrimination experiences among a national sample of female to male transgender individuals. Health \& Social Work, 40(2),134-141. doi: 10.1093/hsw/hlv025

Snelgrove, J. W., Jasudavisius, A. M., Rowe, B. W., Head, E. M., \& Bauer, G. R. (2012). “Completely out-at-sea" with "two-gender medicine": A qualitative analysis of physician-side barriers to providing healthcare for transgender patients. BMC Health Services Research, 12, 110. doi: 10.1186/1472-6963-12-110

*Stotzer, R. L., Ka'opua, L. S. I., \& Diaz, T. P. (2014). Is healthcare caring in Hawai'i? Preliminary results from a health assessment of lesbian, gay, bisexual, transgender, questioning, and intersex people in four counties. Hawai ' $i$ Journal of Medicine \& Public 
Health, 73(6), 175-180.

Tricco, A. C., Antony, J., Zarin, W., Strifler, L., Ghassemi M., Ivory J., ...\& Straus, S. E., (2015). A scoping review of rapid review methods. BMC Medicine, 13, 224. doi: $10.1186 / \mathrm{s} 12916-015-0465-6$

Van Den Bergh, N. \& Crisp, C. (2004). Defining culturally competent practice with sexual minorities: Implications for social work education and practice. Journal of Social Work Education, 40(2), 221-238. doi: 10.1080/10437797.2004.10778491

Wheeler, D. P. \& Dodd, S. (2011). LGBTQ capacity building in health care systems: A social work perspective. Health \& Social Work, 36(4), 307-309.

White-Hughto, J. M., Reisner, S. L., \& Pachankis, J. E. (2015). Transgender stigma and health: A critical review of stigma, determinants, mechanisms, and interventions. Social Science \& Medicine, 147, 222-231. doi: 10.1016/j.socscimed.2015.11.010

Wilkerson, J. M., Rybicki, S., Barber, C. A., \& Smolenski, D. J. (2011). Creating a culturally competent clinical environment for LGBT patients. Journal of Gay \& Lesbian Social Services, 23(3), 376-394. doi: 10.1080/10538720.2011.589254

Winter, S., Diamond, M., Green, J., Karasic, D., Reed, T., Whittle, S., Wylie K. (2016). Transgender people: Health at the margins of society. The Lancet, 388(10042), 390-400. doi: 10.1016/S0140-6736(16)00683-8

Wright, K. B. (2005). Researching internet-based populations: Advantages and disadvantages of online survey research, online questionnaire authoring software packages, and web survey services. Journal of Computer-Mediated Communication, 10, 3. doi: 10.1111/j.1083-6101.2005.tb00259.x 
Zuzelo, P. R. (2014). Improving nursing care for lesbian, bisexual, and transgender women. Journal of Obstetric, Gynecological and Neonatal Nursing, 43(4), 520-530. doi: $10.1111 / 1552-6909.12477$ 
Table 1: Summary of studies on health care discrimination and access barriers against sexual and gender minorities: Prevalence estimates with $95 \%$ confidence intervals (CI)

\begin{tabular}{|c|c|c|c|c|c|}
\hline \multirow[b]{2}{*}{ Study Citation } & \multicolumn{2}{|c|}{ Sample } & \multirow{2}{*}{$\begin{array}{c}\text { Prevalence } \\
\text { Estimate }(\%)\end{array}$} & \multirow[b]{2}{*}{$95 \% \mathrm{CI}$} & \multirow{2}{*}{$\begin{array}{c}\text { PR } \\
95 \% \mathrm{CI} \\
\end{array}$} \\
\hline & Description & Size & & & \\
\hline \multicolumn{6}{|l|}{$\begin{array}{l}\text { Availability and Accommodation } \\
\text { Being denied care }\end{array}$} \\
\hline Lambda Legal (2010) & Transgender & 700 & $26.7^{\mathrm{a}}$ & $23.6,30.1$ & 3.47 \\
\hline Lambda Legal (2010) & LGB & 4,722 & $7.7^{\mathrm{a}}$ & $7.0,8.5$ & $2.95,4.08$ \\
\hline Fredriksen-Goldsen et al. (2011) & Transgender & 174 & $40.4^{\mathrm{a}}$ & $33.2,47.7$ & 3.85 \\
\hline Fredriksen-Goldsen et al. (2011) & LGB & 2,386 & $10.5^{\mathrm{a}}$ & $9.4,11.8$ & $3.06,4.84$ \\
\hline Grant et al. (2011) & Transgender & 6,450 & $19.0^{\mathrm{a}}$ & $18.1,20.0$ & \\
\hline James et al. (2016) & Transgender & 24,112 & $8.0^{\mathrm{b}}$ & $7.7,8.4$ & \\
\hline Reisner et al. (2014) & Transgender & 452 & $5.0^{\mathrm{b}}$ & $3.4,7.5$ & \\
\hline Stotzer et al. (2014) & LGBTQI & 710 & $15.0^{\mathrm{a}}$ & $12.6,17.9$ & \\
\hline \multicolumn{6}{|c|}{ Medical providers' lack of knowledge or had to educate PCP } \\
\hline Grant et al. (2011) & Transgender & 6,450 & $50.0^{\mathrm{a}}$ & $48.8,51.2$ & \\
\hline Bradford et al. (2013) & Transgender & 350 & $20.0^{\mathrm{a}}$ & $16.2,24.5$ & \\
\hline James et al. (2016) & Transgender & 24,112 & $24.0^{\mathrm{b}}$ & $23.5,24.5$ & \\
\hline Reisner et al. (2014) & Transgender & 452 & $29.0^{\mathrm{b}}$ & $25.0,33.3$ & \\
\hline \multicolumn{6}{|l|}{ Affordability } \\
\hline Lack health insurance & & & & & \\
\hline One Colorado (2014) & Transgender & 417 & 14.0 & $10.9,17.6$ & 1.27 \\
\hline One Colorado (2014) & All Coloradans ${ }^{\mathrm{c}}$ & Not available & 11.0 & & \\
\hline Stotzer et al. (2014) & LGBTQI & 710 & 11.1 & $8.9,13.5$ & \\
\hline Grant et al. (2011) & Transgender & 6,450 & 19.0 & $18.1,20.0$ & \\
\hline James et al. (2016) & Transgender & 27,715 & 14.0 & $13.6,14.4$ & \\
\hline Fredriksen-Goldsen et al. (2011) & LGBT & 2,560 & 3.0 & $2.4,3.8$ & \\
\hline
\end{tabular}


Lambda Legal (2010)

Lambda Legal (2010)

James et al. (2016)

Health care professionals being physically rough or abusive

Lambda Legal (2010)

Lambda Legal (2010)

James et al. (2016)

Transgender

LGB

Transgender

\section{Acceptability}

Out to health care provider about being transgender

Bradford et al. (2013)

Grant et al. (2011)

James et al. (2016)

Transgender

Transgender

Transgender

Verbal harassment in a health care setting

Grant et al. (2011)

James et al. (2016)

Transgender

Transgender

Physically attacked in a health care setting

Grant et al. (2011)

James et al. (2016)
350

6,450

27,715

700

4,722

24,112

700

4,722

24,112

6,450

24,112

6,450

24,112
Transgender

$$
\begin{array}{cc}
20.9^{\mathrm{a}} & 18.0,24.0 \\
10.7^{\mathrm{a}} & 9.8,11.6 \\
5.0^{\mathrm{b}} & 4.7,5.3
\end{array}
$$

$\begin{array}{cc}7.8^{\mathrm{a}} & 6.1,10.1 \\ 4.1^{\mathrm{a}} & 3.6,4.7 \\ 2.0^{\mathrm{b}} & 1.8,2.2\end{array}$

43.3

79.0

70.0

$38.3,48.7$

$78.0,80.0$

$69.5,70.5$

$8.0^{\mathrm{a}} \quad 26.9,29.1$

$6.0^{\mathrm{b}} \quad 5.7,6.3$

$2.0^{\mathrm{a}} \quad 1.7,2.4$

$1.0^{\mathrm{b}} \quad 0.8,1.1$

\section{Approachability}

Do not have a regular PCP

Bradford et al. (2013)

Stotzer et al. (2014)

Stotzer et al. (2014)

Fredriksen-Goldsen et al. (2011) LGBT

Transgender
LGBTQI
All Hawaiians
d

LGBT

Note. $\mathrm{PR}=$ Prevalence Ratio between transgender and comparison group. $\mathrm{CI}=$ Confidence Interval. LGB = Lesbian, gay, bisexual. LGBTQI = Lesbian, gay, bisexual, transgender, questioning, intersex. LGBT = Lesbian, gay, bisexual, transgender. PCP = Primary Care Physician 
${ }^{a}$ Lifetime prevalence. ${ }^{b}$ Prevalence in the last 12 months. ${ }^{\mathrm{c}}$ Gallup. ${ }^{\mathrm{d}}$ Institute of Medicine. 
Table 2: Summary of studies on patient postponement of medical care: Prevalence estimates with 95\% confidence intervals (CI)

\begin{tabular}{lcrrr}
\hline \multicolumn{1}{c}{ Study Citation } & \multicolumn{2}{c}{ Sample } & $\begin{array}{c}\text { Prevalence } \\
\text { Estimate (\%) }\end{array}$ & 95\% CI \\
\cline { 2 - 3 } & Description & Size & & \\
Patient postponement of necessary & medical care & & & \\
Grant et al. (2011) & Transgender & 6,450 & $28.0^{\mathrm{a}}$ & $26.9,29.1$ \\
James et al. (2016) & Transgender & 24,112 & $23.0^{\mathrm{b}}$ & $22.5,23.5$ \\
Reisner et al. (2014) & Transgender & 452 & $19.0^{\mathrm{b}}$ & $15.7,22.9$ \\
One Colorado (2014) & Transgender & 417 & $40.0^{\mathrm{b}}$ & $35.5,44.8$ \\
Stotzer et al. (2014) & LGBTQI & 710 & $10.0^{\mathrm{a}}$ & $8.0,12.4$ \\
& & & & \\
Patient postponement of preventive medical care & & & \\
Grant et al. (2011) & Transgender & 6,450 & $33.0^{\mathrm{a}}$ & $31.9,34.2$ \\
Reisner et al. (2014) & Transgender & 452 & $24.0^{\mathrm{b}}$ & $20.2,28.0$
\end{tabular}

Note. CI = Confidence Interval. LGBTQI = Lesbian, gay, bisexual, transgender, questioning, intersex.

${ }^{\mathrm{a}}$ Lifetime prevalence. ${ }^{\mathrm{b}}$ Prevalence in the last 12 months. 